\title{
AMCoR
}

Asahikawa Medical University Repository http://amcor.asahikawa-med.ac.jp/

European journal of pharmacology (2012.Feb) 676巻1-3号:57〜 63 .

Oxicam structure in non-steroidal anti-inflammatory drugs is essential to exhibit Akt-mediated neuroprotection against 1-methyl-4-phenyl pyridinium-induced cytotoxicity

Tasaki Y, Yamamoto J, Omura T, Noda T, Kamiyama N, Yoshida K, Satomi M, Sakaguchi T, Asari M, Ohkubo T, Shimizu K, Matsubara K 


\section{Oxicam structure in non-steroidal anti-inflammatory drugs is essential to exhibit Akt-mediated neuroprotection against}

\section{1-methyl-4-phenyl pyridinium-induced cytotoxicity}

Yoshikazu Tasaki $^{\mathrm{a}}$, Joe Yamamoto ${ }^{\mathrm{a}}$, Tomohiro Omura ${ }^{\mathrm{a}, \mathrm{b}}$, Toshihiro Noda ${ }^{\mathrm{a}}$, Naoya Kamiyama $^{\mathrm{a}}$, Koichi Yoshida ${ }^{\mathrm{a}}$, Machiko Satomi ${ }^{\mathrm{a}}$, Tomoki

Sakaguchi $^{\mathrm{a}}$, Masaru Asari ${ }^{\mathrm{b}}$, Tomoko Ohkubo ${ }^{\mathrm{a}}$, Keiko Shimizu ${ }^{\mathrm{b}}$ and Kazuo Matsubara $^{\mathrm{a}, *}$

a Department of Hospital Pharmacy \& Pharmacology, Asahikawa Medical University, Asahikawa 078-8510, Japan

${ }^{\mathrm{b}}$ Department of Legal Medicine, Asahikawa Medical University, Asahikawa 078-8510, Japan

*Corresponding author at: Department of Hospital Pharmacy \& Pharmacology,

Asahikawa Medical University, 2-1-1-1 Midorigaokahigashi, Asahikawa 078-8510, Japan. Tel.: +81-166-69-3480; fax: +81-166-65-1392.

E-mail address: kmatsuba@asahikawa-med.ac.jp (K. Matsubara). 


\section{ABSTRACT}

In the treatment of Parkinson's disease, potent disease-modifying drugs are still needed to halt progressive dopaminergic neurodegeneration. We have previously shown that meloxicam, an oxicam non-steroidal anti-inflammatory drug (NSAID), elicits a potent neuroprotective effect against 1-methyl-4-phenyl pyridinium $\left(\mathrm{MPP}^{+}\right)$-induced toxicity in human dopaminergic SH-SY5Y neuroblastoma cells. This cyclooxygenase-independent neuroprotection of meloxicam is mediated via the phosphatidylinositol 3-kinase (PI3K)/Akt pathway; however, the specific chemical structure involved in inducing neuroprotection remains unresolved. In this study, we therefore investigated the structure-specific for eliciting the neuroprotective effect by examining a series of NSAIDs against $\mathrm{MPP}^{+}$toxicity in SH-SY5Y cells. Three oxicam-bearing NSAIDs showed potent neuroprotective effects, although none of the other 10 oxicam-nonbearing NSAIDs (3 salicylates, 6 coxibs and 1 polyphenol) or 3 piroxicam analogs (including ampiroxicam, a precursor of piroxicam) exerted any neuroprotection. Tenoxicam and piroxicam prevented $\mathrm{MPP}^{+}$-induced reduction of phosphorylated Akt levels in cells: a protective mechanism similar to that of meloxicam. Therefore, the oxicam structure was likely to be responsible for exhibiting the 
neuroprotection by sustaining survival-signaling in dopaminergic cells. The present results raise the possibility that the oxicam-bearing NSAIDs may serve as potential therapeutic drugs to retard or terminate progression of Parkinson's disease via a novel mechanism.

Keywords: Oxicam; Non-steroidal anti-inflammatory drug; Neuroprotection;

Parkinson's disease; Akt; 1-methyl-4-phenyl pyridinium 


\section{Introduction}

Non-steroidal anti-inflammatory drugs (NSAIDs) are widely used for treatment of diseases accompanied with excessive inflammatory responses, such as rheumatoid arthritis (Gaffo et al., 2006), and several types of pain (Langford and Mehta, 2006) attributed to peripheral inflammation. Neuro-inflammation in the central nervous system has reportedly been suggested to be responsible for the initiation and progression of Parkinson's disease (McGeer and McGeer, 2004; Ouchi et al., 2005). The mechanism of inflammation suppression of NSAIDs in the central nervous system arises from the inhibition of cyclooxygenase (COX), which has been activated in microglial cells adjacent to the affected neurons during inflammation onset (McGeer et al., 1988). Indeed, non-aspirin NSAIDs have been reported to be beneficial for the treatment of Parkinson's disease in several epidemiological studies (Chen et al., 2003; Hernan et al., 2006; Ton et al., 2006). Efficacy of this anti-inflammatory mechanism of NSAIDs for Parkinson's disease has also been experimentally supported by cellular and animal models (Esposito et al., 2007; Teismann and Ferger, 2001; Wang et al., 2005).

In addition to suppression of inflammation, one of the NSAIDs, meloxicam, has been found to exhibit direct neuroprotective activity in human dopaminergic SH-SY5Y 
neuroblastoma cells (without microglia) in our previous study (Tasaki et al., 2010).

COX-1 and COX-2 are known to be expressed and to produce prostaglandin E2 in the SH-SY5Y cells (Alique et al., 2007). However, the neuroprotective effect has not been observed in other typical NSAIDs, such as indomethacin and ibuprofen and potently selective COX-2 inhibitors. The neuroprotection of meloxicam is induced via specifically maintaining PI3K/Akt of the intracellular signaling pathways without the involvement of COX-1 or COX-2 (Tasaki et al., 2010). There is heterogeneity in the chemical structures of NSAIDs that determine the isoform selectivity and potency of COX-1 and COX-2 inhibition (Taketo, 1998). However, the relationship between the chemical structure and neuroprotective activity has not been examined to date, especially in the case of clinical applications of NSAIDs in Parkinson's disease patients. Therefore, it is essential to elucidate the structural specificity of NSAIDs, such as meloxicam, in neuroprotection.

The present study attempted to identify the structural specificity responsible for inducing neuroprotective effect in NSAIDs by examining the protective effects of a series of NSAIDs on 1-methyl-4-phenyl pyridinium (MPP ${ }^{+}$-induced neuronal death. Furthermore, the involvement of the protective signaling pathway, PI3K/Akt, was studied to identify and clarify the neuroprotective sites and mechanism, respectively. 


\section{Materials and methods}

\subsection{Materials}

All primary antibodies were obtained from Cell Signaling Technology (Danvers, MA, USA). Horseradish peroxidase (HRP)-conjugated anti-rabbit IgG antibody from donkey (GE Healthcare; Little Chalfont, UK) was used in the experiments. NSAIDs such as celecoxib (BioVision, Inc., Mountain View, CA, USA), meloxicam and tenoxicam (Sigma; St Louis, MO, USA), piroxicam (ENZO life Sciences; Farmingdale, NY, USA) and $\mathrm{MPP}^{+}$(Sigma; St Louis, MO, USA) were commercially acquired. Piroxicam analog G (Methyl 4-hydroxy-2H-1,2-benzothiazine-3-carboxylate methyl ester 1,1-dioxide) and piroxicam analog J (Methyl 4-hydroxy-2-methyl-2H1,2-benzothiazine-3-carboxylate methyl ester 1,1-dioxide) were from Toronto Research Chemicals (North York, ON, Canada), and ampiroxicam from Wako (Osaka, Japan). The other NSAIDs were from Cayman Chemical (Ann Arbor, MI, USA), including APHS (2-(2-heptynylthio)-phenol acetate), SC-560 (5-(4-chlorophenyl)-1- 
(4-(methoxyphenyl)-3-(trifluoromethyl)-1H-pyrazole), CAY10452 (4-[5-phenyl-3-

(trifluoromethyl)-1H-pyrazol-1-yl]-benzensulfonamide), SC-58125 (5-(4-fluorophenyl)-

1-[4-(methylsulfonyl)phenyl]-3-(trifluoromethyl)-1H-pyrazole), and t-resveratrol

((E)-5-[2-(4-hydroxyphenyl)ethenyl]-1,3-benzenediol). All other chemicals (Wako;

Osaka, Japan) used in this experiments were either of the highest or analytical grade.

\subsection{Cell culture and drug treatment}

SH-SY5Y human neuroblastoma cells were maintained in Dulbecco's modified

Eagle's medium containing $10 \%$ heat-inactivated fetal bovine serum, penicillin (100

$\mathrm{U} / \mathrm{ml})$ and streptomycin $(100 \mu \mathrm{g} / \mathrm{ml})$ before being seeded onto a 6- or 96-well plate at

$1.5 \times 10^{5}$ cells $/ \mathrm{cm}^{2}$ and cultured in a humidified incubator $\left(95 \%\right.$ air and $\left.5 \% \mathrm{CO}_{2}\right)$ for 24

$\mathrm{h}$ at $37^{\circ} \mathrm{C}$. After rinsing, cells in the plates were treated with serum-free culture media

containing a test-agent dissolved in ethanol or dimethyl sulfoxide (final $0.1 \%$ ) and the

antibiotics. Concurrently, the cells were co-incubated with $\mathrm{MPP}^{+}$(final concentration: 5 $\mathrm{mM}$ ) and/or LY294002 (final concentration: $10 \mu \mathrm{M}$ ) for $4 \mathrm{~h}$ (Western blot preparations)

or $24 \mathrm{~h}$ (evaluation of cell toxicity). 


\subsection{Evaluation of cell toxicity}

Cell viability was assessed by measuring the optical density at $450 \mathrm{~nm}$ with a microplate reader (ImmunoMini NJ-2300, System Instruments, Tokyo, Japan) after 2.5-h loading with WST-8 test reagent (Dojindo, Kumamoto, Japan), according to the manufacture's instruction. The relative cell viability was calculated as percentage of vehicle control in the absence of $\mathrm{MPP}^{+}$. Cell damage was determined by lactate dehydrogenase ( $\mathrm{LDH})$ leakage into the culture medium from cells using the LDH cytotoxic test (Wako, Osaka, Japan). LDH leakage was determined by measuring the optical density at $540 \mathrm{~nm}$. When cells were treated with culture medium containing $1 \%$ Tween 20, LDH leakage into the culture medium was designated as $100 \%$.

\subsection{Western blotting}

After rinsing with $1 \mathrm{ml}$ ice-cold phosphate-buffered saline, cells were collected and sonicated in $100 \mu 1$ of ice-cold lysis buffer containing $20 \mathrm{mM}$ Tris buffer (pH 7.5), 250 $\mathrm{mM} \mathrm{NaCl}, 1 \%$ Triton X-100, 1 mM EDTA, 1 mM dithiothreitol, $10 \mathrm{mM} \mathrm{NaF,} 2 \mathrm{mM}$ sodium orthovanadate and the protease-inhibitor cocktail (EDTA-free complete type; 
Roche Applied Science, Switzerland). Cellular debris was removed from the lysate by centrifugation $(15,000 \mathrm{x} \mathrm{g}, 10 \mathrm{~min})$, and protein contents of supernatant were determined using the BCA protein assay kit (Thermo Fisher Scientific, Rockford, IL, USA). After boiling with Laemmli buffer for $5 \mathrm{~min}$, proteins $(20 \mu \mathrm{g})$ separated by $7.5 \%$ SDS-polyacrylamide gel electrophoresis were electrophoretically transferred onto a polyvinylidene fluoride membrane. The membrane was sequentially treated with Block Ace (DS Pharma Biomedical, Osaka, Japan) and incubated overnight at $4^{\circ} \mathrm{C}$ with anti-phosphorylated-Akt (Ser 473, $1: 1,000)$ or anti-Akt $(1: 5,000)$ from rabbit in 10 $\mathrm{mM}$ Tris buffer ( $\mathrm{pH} 7.5$ ) containing $0.9 \% \mathrm{NaCl}, 0.05 \%$ Tween 20 and $10 \%$ methanol (TBST). For the other antibody for $\beta$-actin the dilution rate of $1: 2,000$ in TBST was used. The membrane was then washed three times with TBST and probed with the HRP-conjugated anti-rabbit IgG antibody from donkey $(1: 10,000)$ for $1 \mathrm{~h}$ at room temperature. The washing procedure was repeated before the membrane was treated with a chemiluminescent reagent (ECLplus; GE Healthcare, Little Chalfont, UK). The proteins were visualized using an LAS3000 image-analyzer (FUJIFILM, Tokyo, Japan).

\subsection{Statistical Analysis}


Data were analyzed by one factorial ANOVA followed by the Tukey's multiple comparison test for post-hoc significance testing.

\section{Results}

3.1. Effects of salicylates, coxibs, oxicams, and a polyphenol belonging to NSAIDs on neuronal toxicity induced by $M P P^{+}$exposure

Thirteen NSAIDs comprising 3 salicylates (valeroyl salicylate, aspirin and APHS), 6 coxibs (SC-560, CAY10452, valdecoxib, celecoxib, SC-58125 and licofelone), 3 oxicams (piroxicam, tenoxicam and meloxicam) and 1 polyphenol ( $t$-resveratrol) were each evaluated at $30 \mu \mathrm{M}$ concentration by the cell viability and LDH leakage assays in $\mathrm{MPP}^{+}$-exposed SH-SY5Y cells. Only 3 oxicams of the 13 tested NSAIDs showed neuroprotection in both assays: i.e. cell viability and LDH leakage (Fig. 1). The neuroprotective activities of piroxicam and tenoxicam were elicited in a dose-dependent manner (Fig. 2). All non-oxicam drugs at lower concentrations (1, 3 and $10 \mu \mathrm{M})$ were also tested by the both assays, however, any protective effect was not observed. 
3.2. Effects of piroxicam -analogs on neuronal toxicity induced by $M P P^{+}$exposure

To identify the structure specificity, three commercially available analogs of piroxicam (Fig. 3A), including ampiroxicam (the in vivo precursor of piroxicam), were tested by the cell viability and LDH leakage assays. None of these analogs showed any neuroprotective effect (Fig. 3B and C).

3.3. Effects of PI3K inhibitor, LY294002, on neuroprotective activities of piroxicam and tenoxicam

We have previously identified a PI3K inhibitor (LY294002) that abolished the neuroprotective effect of meloxicam against $\mathrm{MPP}^{+}$toxicity (Tasaki et al., 2010). To investigate if the neuroprotective activities of piroxicam and tenoxicam were also mediated by cell survival signaling in the PI3K/Akt pathway, the effect of LY294002 on neuroprotection were evaluated by the cell viability and LDH leakage assays. Interestingly, the protective effects of piroxicam and tenoxicam were completely abolished by LY294002 in both assays (Fig. 4). 
3.4. Involvement of PI3K/Akt pathway in the neuroprotection by piroxicam and tenoxicam

Since LY294002 blocked the neuroprotection of tenoxicam and piroxicam against $\mathrm{MPP}^{+}$-induced toxicity, the amount of phosphorylated Akt (pAkt) (Ser 473), which is an activation marker of PI3K/Akt pathway, was measured $4 \mathrm{~h}$ after the incubation with $\mathrm{MPP}^{+}$by the Western blot analysis. Piroxicam and tenoxicam significantly $(p<0.001$ or 0.05) reversed the $\mathrm{MPP}^{+}$-induced reduction of pAkt levels (Fig. 5A and C). LY294002 completely $(p<0.001)$ abolished the recovery of pAkt by these oxicams (Fig. 5A and C). Neither piroxicam nor tenoxicam per se affected pAkt in the presence or absence of $\mathrm{MPP}^{+}$. Note that none of the treatments affected the total Akt levels (Fig. 5B and D). The Akt antibody used in this study recognized two proteins, which were considered to be isoforms of Akt (Figs. 5 and 6). On the other hand, pAkt (473) antibody recognized the phosphorylation of the lower protein band of two which were recognized by the Akt antibody.

3.5. Effects of celecoxib and other coxibs on phosphorylated Akt in neuroblastoma 
SH-SY5Y with or without MPP

Since celecoxib has been known to disrupt Akt signaling in prostate and breast cancer cells (Hsu et al., 2000; Kucab et al., 2005), we examined if coxibs (including celecoxib) would deactivate Akt signaling in SH-SY5Y neuroblastoma cells. Five coxibs $(30 \mu \mathrm{M})$ were evaluated if their effects would affect pAkt (Ser 473) and Akt levels after 4-h incubation with or without $\mathrm{MPP}^{+}$. None of the five coxibs affected either pAkt (Ser 473) or Akt expression independently of the presence of $\mathrm{MPP}^{+}$(Fig. 6).

\section{Discussion}

In this study, we investigated 13 NSAIDs as possible candidate drugs for the treatment of Parkinson's disease. In our current research, there were two major new findings. Firstly, NSAIDs having an oxicam structure (Fig. 7) exerted direct neuroprotective activity against $\mathrm{MPP}^{+}$-induced toxicity in SH-SY5Y cells. Secondly, the intracellular signaling pathway related to the neuroprotection of oxicam-bearing NSAIDs served to maintain the pro-survival cascade, PI3K/Akt. This finding coincides 
well with our previously published data on meloxicam (Tasaki et al., 2010). Apart from these major findings, coxib-bearing NSAIDs, including celecoxib did not affect PI3K/Akt signaling in dopaminergic human neuroblastoma SH-SY5Y cells.

NSAIDs are divided into groups with various chemical structures, such as propionic acids, arylacetic acids, salicylates, coxibs, oxicams and others. Ibuprofen and indomethacin, which are respectively the typical drugs of propionic acids and arylacetic acids, show no in vitro neuroprotective activity against $\mathrm{MPP}^{+}$toxicity in SH-SY5Y cells (Tasaki et al., 2010). In addition to the previous data (Tasaki et al., 2010), salicylates (e.g., aspirin), coxibs (e.g., celecoxib) and polyphenols (e.g., t-resveratrol) were confirmed not to exhibit any neuroprotective property. However, oxicam-bearing piroxicam and tenoxicam showed potent neuroprotective effects in a concentration-dependent manner similar to that of meloxicam. Based on our findings on the chemical structure to date, only oxicam-bearing NSAIDs were expected to have neuroprotective activity. In terms of neuroprotective effect, this is partly supported by a previous finding that piroxicam, but not ibuprofen, attenuates $\mathrm{MPP}^{+}$-induced toxicity in Neuro-2A neuroblastoma cells (Soliman et al., 2009).

To further investigate the relationship between the oxicam structure and neuroprotective activity, three piroxicam derivatives were evaluated. In the case of 
ampiroxicam (a pro-drug of piroxicam), the absence of neuroprotection is probably because of the structurally bulky addition of 1-(ethoxycarbonyloxy) ethoxy group to the hydroxy group in piroxicam. As for the other two piroxicam derivatives (which lack the 2-pyridyl amine group from piroxicam), similar negative results of neuroprotective activity were noted as well. This structure-specific result strongly indicates that the presence of an oxicam structure (Fig. 7) is critical for oxicams to exert the neuroprotective effect. As far as we know, there has not been a single article that correlates on the structure-activity relationship on COX-independent neuroprotective property of NSAIDs.

The second major finding depicts that the neuroprotective intracellular signaling pathway affected by piroxicam and tenoxicam coincides with the mechanism of meloxicam: viz., maintenance of the PI3K/Akt cascade. Reduction of pAkt levels by $\mathrm{MPP}^{+}$, which would reduce survival-signaling in cells, was completely reversed to non-treatment control levels by the presence of piroxicam or tenoxicam at $4 \mathrm{~h}$ after incubation when apoptosis was yet to be observed (data not shown). This result suggests that preservation of the pAkt level may lead to cell survival against $\mathrm{MPP}^{+}$cytotoxicity. In addition, a PI3K inhibitor, LY294002, cancelled the neuroprotective effects of piroxicam and tenoxicam not only in cell viability and LDH assays but also in the 
Western blot analysis of pAkt, thus indicating that the neuroprotective mechanism was mediated via PI3K/Akt. This finding coincides with results of our previous elucidation of meloxicam (Tasaki et al., 2010).

Interestingly, piroxicam, tenoxicam, and meloxicam, per se, did not increase pAkt in cells untreated with $\mathrm{MPP}^{+}$. Previous literature has suggested that stabilization of the PI3K/Akt pathway is an important mechanism by which caffeine, dopamine D3 agonists, nerve growth factor, and brain-derived neurotrophic factor have prevented cell death in SH-SY5Y cells against MPP ${ }^{+}$exposure (Encinas et al., 1999; Halvorsen et al., 2002; Nakaso et al., 2008; Presgraves et al., 2004). Note that these molecules elicit PI3K/Akt activation by themselves: i.e., caffeine per se activates phosphorylation of Akt via antagonism of adenosine A2a transmission (Nakaso et al., 2008). However, the present results indicate that the site of action of oxicams would be different from that of caffeine or other PI3K/Akt-activating substances described above. Since oxicams did not promote cell growth in this study, the cell death-prevention mechanism of oxicams might be due to the inhibition of a certain molecule that reduced phosphorylation of Akt by $\mathrm{MPP}^{+}$. Further studies to identify and elucidate the target molecule or the site of oxicam action in maintaining the cell survival-signaling pathway are warranted.

The other finding was that coxibs neither affected cell viability nor reduced pAkt 
levels in our neuroblastoma cellular assays, although celecoxib has been reported to reduce pAkt level and to inhibit growth of cancer cells (Hsu et al., 2000; Kucab et al., 2005). The discrepancy between previous (Hsu et al., 2000; Kucab et al., 2005) and present results could be derived from factors such as the cell type and culture condition. This anticancer effect of celecoxib might be limited to proliferous cancer cells (Jetzt et al., 2003). To confirm this hypothesis, we investigated the effect of 5 coxibs on pAkt levels in nonproliferous SH-SY5Y neuroblastoma cells. The pAkt levels were not affected by the coxib agents tested with or without $\mathrm{MPP}^{+}$, suggesting that coxibs could not reduce phosphorylation of Akt, at least in nonproliferating SH-SY5Y neuroblastoma cells.

In conclusion, our results suggest that oxicam-bearing NSAIDs could serve as potential therapeutic drugs for Parkinson's disease. The oxicam-bearing NSAIDs could act as disease-modifying agents to inhibit or delay neuronal dopaminergic cell degeneration by maintaining PI3K/Akt in addition to COX inhibition, which would also attenuate neural inflammation in the central nervous system. Indeed, activation and/or maintenance of the PI3K/Akt pathway could serve as a potential therapeutic target for the treatment of Parkinson's disease (Greene et al., 2011; Timmons et al., 2009). Our findings would perfectly dovetail with this hypothesis. Further studies in vivo to prove 
this hypothesis are needed for clinical application, although meloxicam has been shown to be neuroprotective in the MPTP-treated mice (Teismann and Ferger, 2001).

Therefore, clinical trials of oxicams for the treatment of Parkinson's disease may prove practical and useful since oxicam-bearing NSAIDs are in current use.

\section{Acknowledgements}

This work is supported by the Japanese governmental Grant-in-Aid for Scientific

Research, KAKENHI (22590129). 


\section{References}

Alique, M., Herrero, J. F., Lucio-Cazana, F. J., 2007. All-trans retinoic acid induces COX-2 and prostaglandin E2 synthesis in SH-SY5Y human neuroblastoma cells: involvement of retinoic acid receptors and extracellular-regulated kinase $1 / 2$. J. Neuroinflammation 4,1 .

Chen, H., Zhang, S.M., Hernan, M.A., Schwarzschild, M.A., Willett, W.C., Colditz, G.A., Speizer, F.E., Ascherio, A., 2003. Nonsteroidal anti-inflammatory drugs and the risk of Parkinson disease. Arch. Neurol. 60, 1059-1064.

Encinas, M., Iglesias, M., Llecha, N., Comella, J.X., 1999. Extracellular-regulated kinases and phosphatidylinositol 3-kinase are involved in brain-derived neurotrophic factor-mediated survival and neuritogenesis of the neuroblastoma cell line SH-SY5Y. J. Neurochem. 73, 1409-1421.

Esposito, E., Di Matteo, V., Benigno, A., Pierucci, M., Crescimanno, G., Di Giovanni, G., 2007. Non-steroidal anti-inflammatory drugs in Parkinson's disease. Exp. Neurol. $205,295-312$.

Gaffo, A., Saag, K.G., Curtis, J.R., 2006. Treatment of rheumatoid arthritis. Am. J. Health Syst. Pharm. 63, 2451-2465.

Greene, L.A., Levy, O., Malagelada, C., 2011. Akt as a victim, villain and potential hero 
in Parkinson's Disease pathophysiology and treatment. Cell. Mol. Neurobiol. 31, 969-978.

Halvorsen, E.M., Dennis, J., Keeney, P., Sturgill, T.W., Tuttle, J.B., Bennett, J.B., Jr., 2002. Methylpyridinium (MPP(+))- and nerve growth factor-induced changes in pro- and anti-apoptotic signaling pathways in SH-SY5Y neuroblastoma cells. Brain Res. 952, 98-110.

Hernan, M.A., Logroscino, G., Garcia Rodriguez, L.A., 2006. Nonsteroidal anti-inflammatory drugs and the incidence of Parkinson disease. Neurology 66, 1097-1099.

Hsu, A.L., Ching, T.T., Wang, D.S., Song, X., Rangnekar, V.M., Chen, C.S., 2000. The cyclooxygenase-2 inhibitor celecoxib induces apoptosis by blocking Akt activation in human prostate cancer cells independently of Bcl-2. J. Biol. Chem. 275, 11397-11403.

Jetzt, A., Howe, J.A., Horn, M.T., Maxwell, E., Yin, Z., Johnson, D., Kumar, C.C., 2003. Adenoviral-mediated expression of a kinase-dead mutant of Akt induces apoptosis selectively in tumor cells and suppresses tumor growth in mice. Cancer Res. 63, $6697-6706$.

Kucab, J.E., Lee, C., Chen, C.S., Zhu, J., Gilks, C.B., Cheang, M., Huntsman, D., 
Yorida, E., Emerman, J., Pollak, M., Dunn, S.E., 2005. Celecoxib analogues disrupt Akt signaling, which is commonly activated in primary breast tumours. Breast Cancer Res. 7, R796-807.

Langford, R.M., Mehta, V., 2006. Selective cyclooxygenase inhibition: its role in pain and anaesthesia. Biomed Pharmacother. 60, 323-328.

McGeer, P.L., Itagaki, S., Boyes, B.E., McGeer, E.G., 1988. Reactive microglia are positive for HLA-DR in the substantia nigra of Parkinson's and Alzheimer's disease brains. Neurology. 38, 1285-1291.

McGeer, P.L., McGeer, E.G., 2004. Inflammation and the degenerative diseases of aging. Ann. N. Y. Acad. Sci. 1035, 104-116.

Nakaso, K., Ito, S., Nakashima, K., 2008. Caffeine activates the PI3K/Akt pathway and prevents apoptotic cell death in a Parkinson's disease model of SH-SY5Y cells. Neurosci. Lett. 432, 146-150.

Ouchi, Y., Yoshikawa, E., Sekine, Y., Futatsubashi, M., Kanno, T., Ogusu, T., Torizuka, T., 2005. Microglial activation and dopamine terminal loss in early Parkinson's disease. Ann Neurol. 57, 168-175.

Presgraves, S.P., Borwege, S., Millan, M.J., Joyce, J.N., 2004. Involvement of dopamine $\mathrm{D}(2) / \mathrm{D}(3)$ receptors and BDNF in the neuroprotective effects of S32504 and 
pramipexole against 1-methyl-4-phenylpyridinium in terminally differentiated SH-SY5Y cells. Exp. Neurol. 190, 157-170.

Soliman, Y., Jackson, T., Mazzio, E., Soliman, K.F., 2009. The effects of piroxicam in the attenuation of MPP+/MPTP toxicity in vitro and in vivo. Neurochem Res. 34, 304-310.

Taketo, M.M., 1998. Cyclooxygenase-2 inhibitors in tumorigenesis (part I). J. Natl. Cancer Inst. 90, 1529-1536.

Tasaki, Y., Omura, T., Yamada, T., Ohkubo, T., Suno, M., Iida, S., Sakaguchi, T., Asari, M., Shimizu, K., Matsubara, K., 2010. Meloxicam protects cell damage from 1-methyl-4-phenyl pyridinium toxicity via the phosphatidylinositol 3-kinase/Akt pathway in human dopaminergic neuroblastoma SH-SY5Y cells. Brain Res. 1344, $25-33$.

Teismann, P., Ferger, B., 2001. Inhibition of the cyclooxygenase isoenzymes COX-1 and COX-2 provide neuroprotection in the MPTP-mouse model of Parkinson's disease. Synapse. 39, 167-174.

Timmons, S., Coakley, M.F., Moloney, A.M., C, O.N., 2009. Akt signal transduction dysfunction in Parkinson's disease. Neurosci Lett. 467, 30-35.

Ton, T.G., Heckbert, S.R., Longstreth, W.T., Jr., Rossing, M.A., Kukull, W.A., Franklin, 
G.M., Swanson, P.D., Smith-Weller, T., Checkoway, H., 2006. Nonsteroidal anti-inflammatory drugs and risk of Parkinson's disease. Mov. Disord. 21, 964-969.

Wang, T., Pei, Z., Zhang, W., Liu, B., Langenbach, R., Lee, C., Wilson, B., Reece, J.M., Miller, D.S., Hong, J.S., 2005. MPP+-induced COX-2 activation and subsequent dopaminergic neurodegeneration. FASEB J. 19, 1134-1136. 


\section{Figure legends}

Fig. 1. Effects of non-steroidal anti-inflammatory drugs (NSAIDs) (three salicylates, six coxibs, three oxicams and one polyphenol NSAID) on neuronal toxicity induced by 1-methyl-4-phenyl pyridinium (MPP ${ }^{+}$) exposure. SH-SY5Y cells were incubated with $30 \mu \mathrm{M}$ of the indicated agents for $24 \mathrm{~h}$ in the presence (solid column) or absence (open column) of $5 \mathrm{mM} \mathrm{MPP}{ }^{+}$. Cell toxicity was evaluated by cell viability (A) and LDH assays (B). The relative cell viability was calculated as percentage of vehicle control in the absence of $\mathrm{MPP}^{+}$. Data are expressed as the mean \pm S.E.M. of at least three independent experiments. Differences where $P<0.05\left(^{*}\right)$ and $<0.001(* *)$ indicated significant amelioration, and difference where $P<0.05\left(^{+}\right)$indicated significant deterioration when compared with the corresponding vehicle-treated group by the Tukey's test for one-factorial ANOVA.

Fig. 2. Concentration-dependent neuroprotective effects of piroxicam and tenoxicam on SH-SY5Y cells. SH-SY5Y cells were incubated with either oxicam at the indicated concentrations for $24 \mathrm{~h}$ in the presence (solid column) or absence (open column) of 5 $\mathrm{mM} \mathrm{MPP}^{+}$. Cell toxicity was evaluated by cell viability (A and C) and LDH assays (B 
and D). The relative cell viability was calculated as percentage of vehicle control in the absence of $\mathrm{MPP}^{+}$. Data are expressed as the mean \pm S.E.M. of at least three independent experiments. Differences where $P<0.05(*)$ and $<0.001(* *)$ in cell toxicity were significantly different when compared with the corresponding vehicle group by the Tukey's test for one-factorial ANOVA.

Fig. 3. Structures of piroxicam analogs (A) and their effects against $\mathrm{MPP}^{+}$exposure. Cell toxicity was evaluated by the cell viability (B) and LDH assays (C) in the presence (solid column) or absence (open column) of $5 \mathrm{mM} \mathrm{MPP}^{+}$and $30 \mu \mathrm{M}$ indicated agents. The relative cell viability was calculated as percentage of vehicle control in the absence of $\mathrm{MPP}^{+}$. No statistical difference between any 2 groups was observed by the one-factorial ANOVA.

Fig. 4. Cancelling effects of LY294002 on the neuroprotective activities of piroxicam and tenoxicam against $\mathrm{MPP}^{+}$-induced toxicity. Piroxicam and tenoxicam $(30 \mu \mathrm{M})$ were examined in cell viability (A and C) and LDH assays (B and D) after a 24-h incubation with or without LY294002 $(10 \mu \mathrm{M})$. Differences in cell toxicity where $P<0.05\left(^{*}\right)$ and $<0.001(* *)$ were significant between the two groups indicated by the Tukey's test for 
one-factorial ANOVA.

Fig. 5. Effects of piroxicam and tenoxicam on phosphorylation of Akt. The amounts of Akt phosphorylation (Ser 473; A and C) and total Akt (B and D) were respectively determined after 4-h incubation with $\mathrm{MPP}^{+}(5 \mathrm{mM})$ and either piroxicam or tenoxicam $(30 \mu \mathrm{M})$ with or without a PI3K inhibitor, LY294002 (10 $\mu \mathrm{M})$. Each value represents the mean \pm S.E.M. of 4 independent experiments, with a representative image on western blotting of phospholylated Akt (Ser 473), Akt or $\beta$-actin. Differences in amount, where $P<0.05\left(^{*}\right)$ and $<0.001(* *)$, were significant when verified by the one-way factorial ANOVA followed by the Tukey's test.

Fig. 6. Effects of coxib NSAIDs on phosphorylation of Akt. The amounts of Akt phosphorylation (Ser 473) (A and C) and total Akt (B and D) were determined after 4-h incubation with each coxib $(30 \mu \mathrm{M})$ in the absence (A and B) or presence $(\mathrm{C}$ and $\mathrm{D})$ of $\mathrm{MPP}^{+}$. Each value represents the mean \pm S.E.M. of 3 or 4 independent experiments, with representative images on western blotting of phospholylated Akt (pAkt; Ser 473), Akt or $\beta$-actin. No statistical difference was observed in amount of pAkt (Ser 473) or Akt among experimented groups when verified by the one-way factorial ANOVA. 
Fig.7. Essential structural features of oxicams with regard to elicitation of neuroprotection against $\mathrm{MPP}^{+}$toxicity.

Supp Fig.1. Effects of NSAIDs (three salicylates, six coxibs, three oxicams and a polyphenol NSAID) on neuronal toxicity induced by the MPP ${ }^{+}$exposure. SH-SY5Y cells were incubated with lower concentrations $(1,3$ and $10 \mu \mathrm{M})$ of the indicated agents in Fig. 1 for $24 \mathrm{~h}$ in the presence (solid or hatched column) or absence (open column) of $5 \mathrm{mM} \mathrm{MPP}^{+}$. Aspirin was also evaluated at higher concentrations (100 and $\left.1000 \mu \mathrm{M}\right)$. Cell toxicity was evaluated by cell viability (A) and LDH assays (B). Data are expressed as the mean \pm S.E.M. of four independent experiments. Differences, where $P$ $<0.05(*)$ and $<0.001(* *)$, were significant in the cell viability or the LDH assays, when compared with the corresponding vehicle-treated group by the Tukey's test for one-factorial ANOVA. 
Fig.1.

A

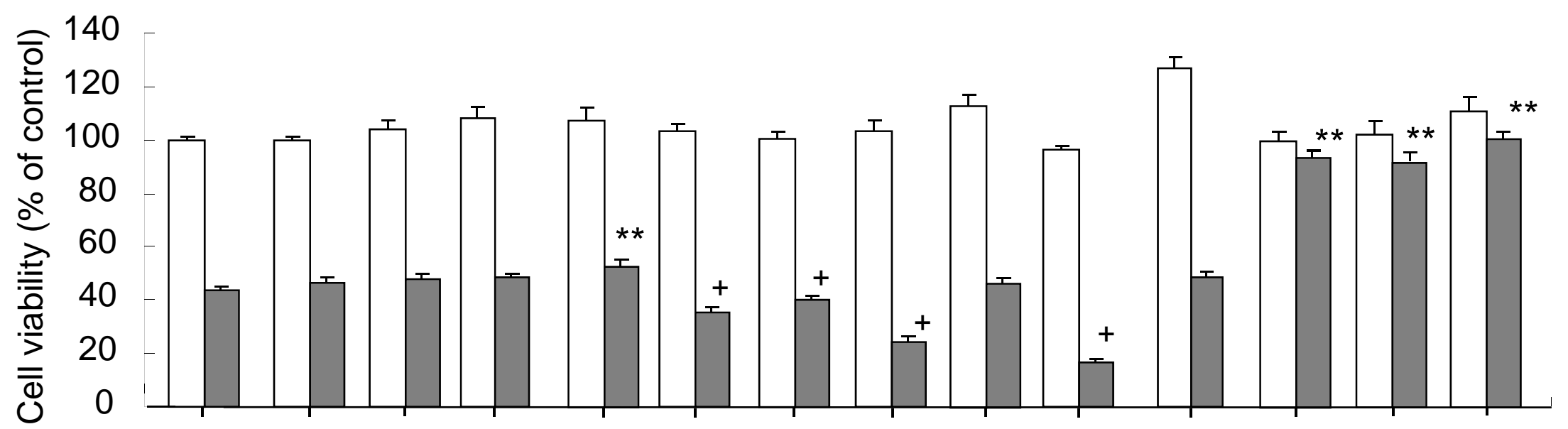

B 25

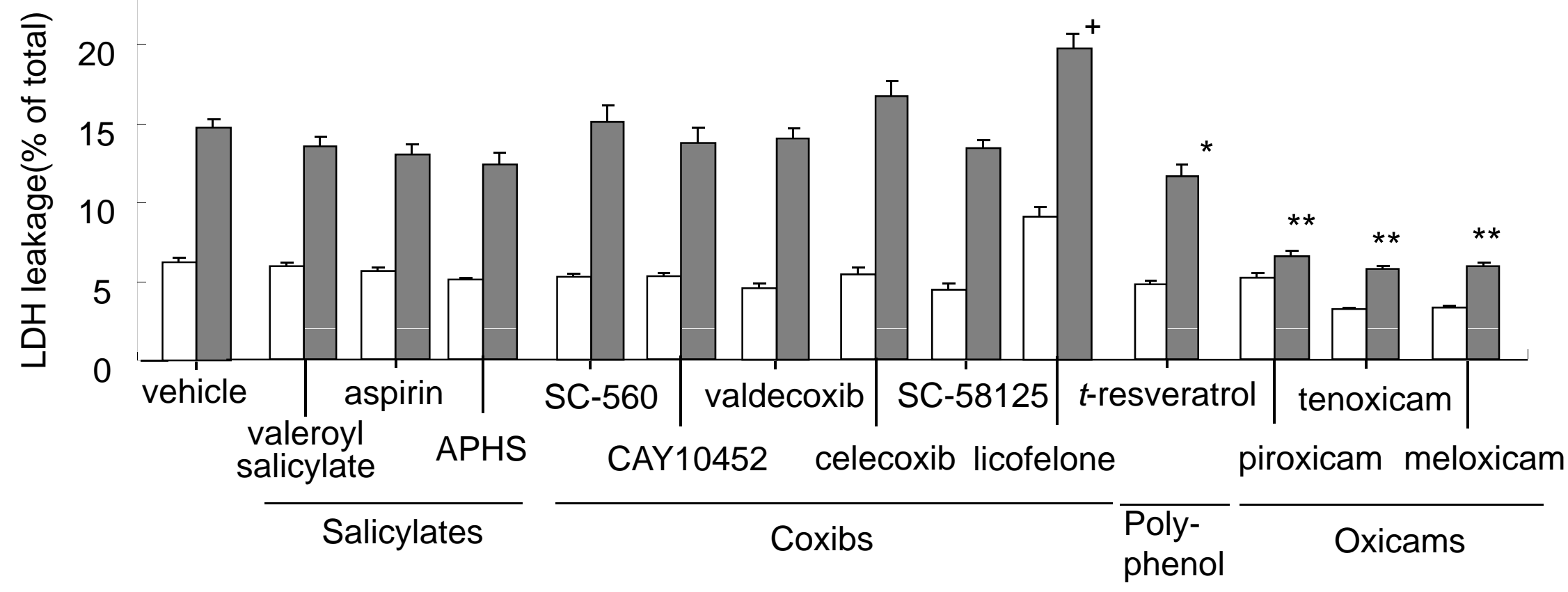


Fig.2.

A

C

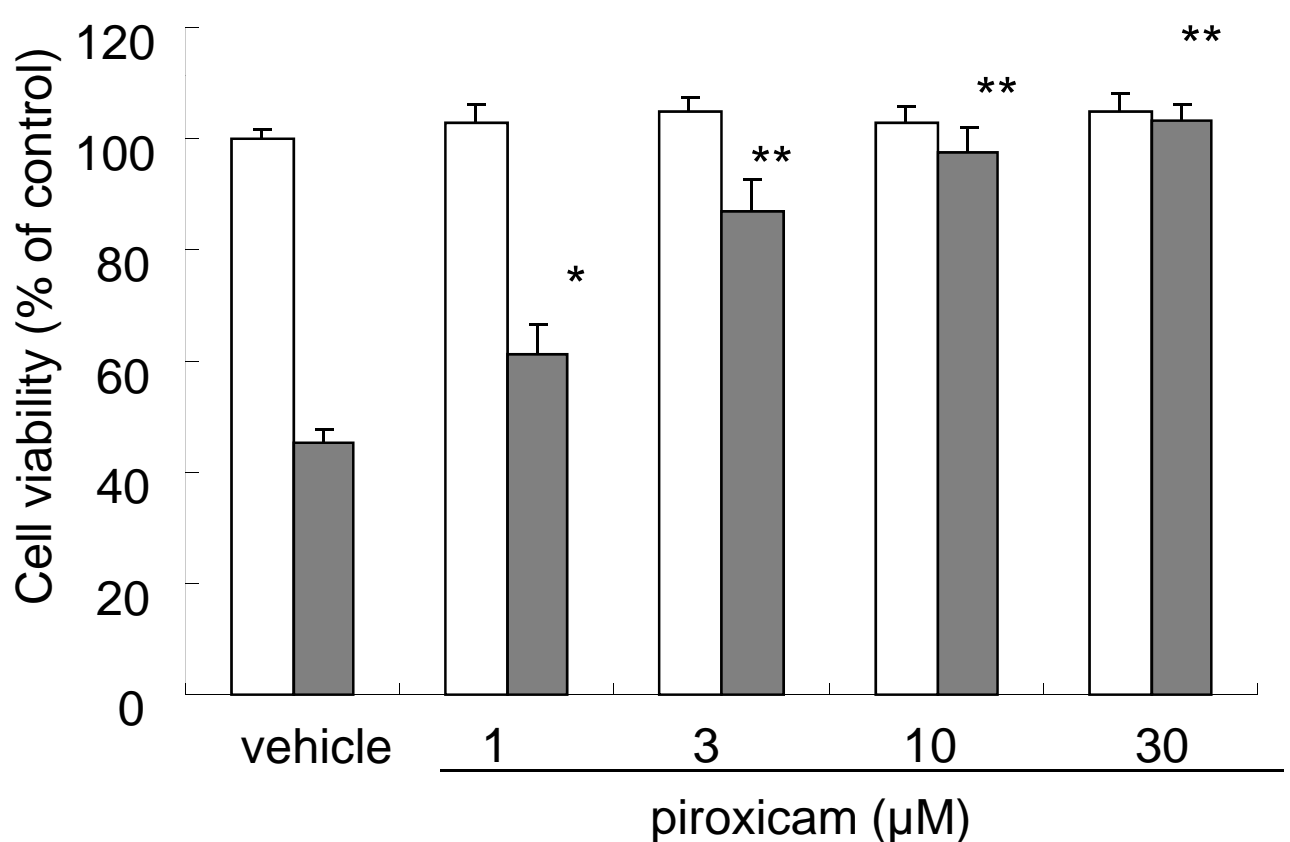

B

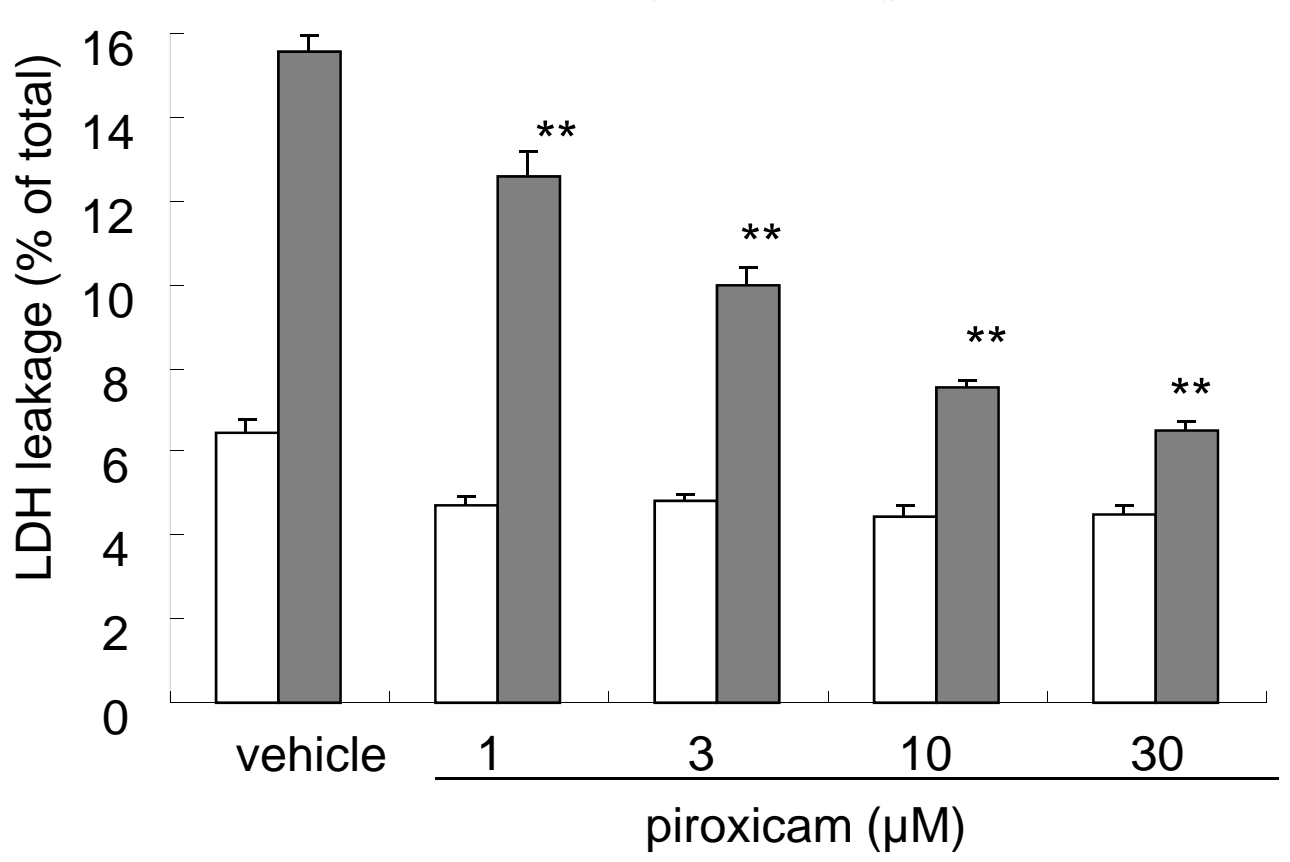

\section{D}

ฮิ 14

吕 12

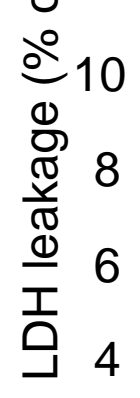

2

0

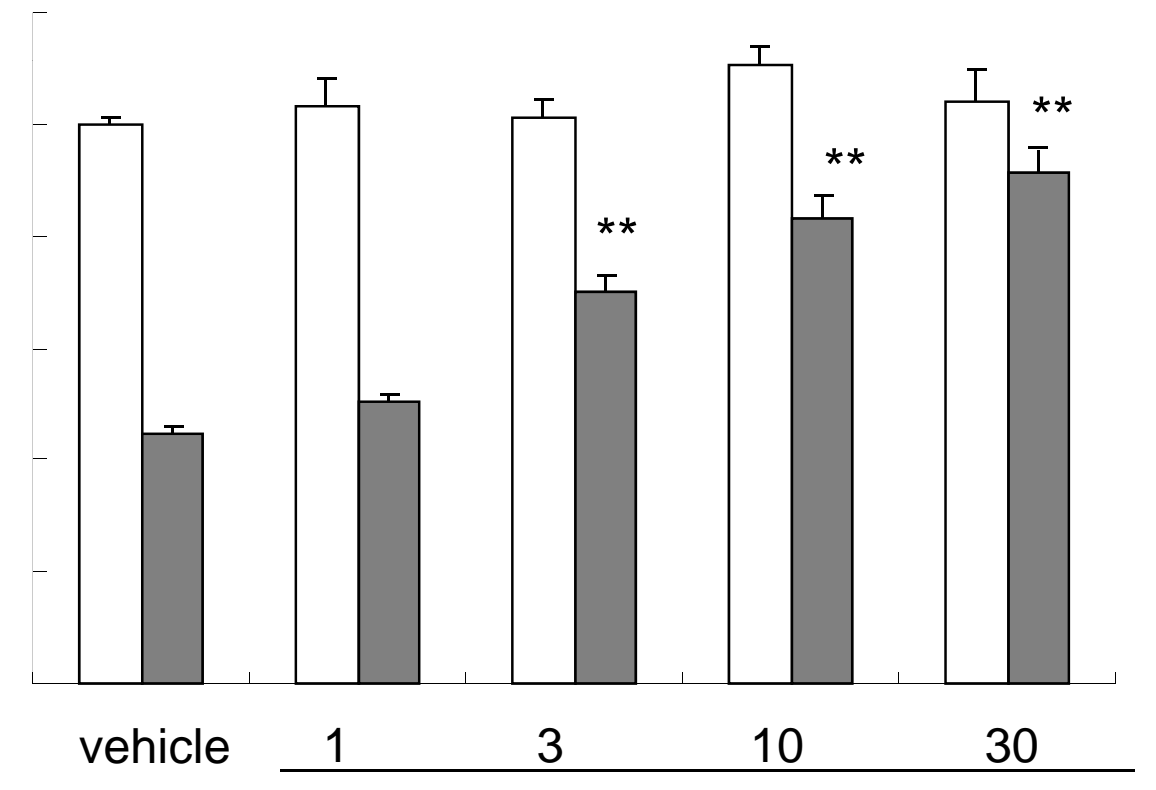

tenoxicam $(\mu \mathrm{M})$

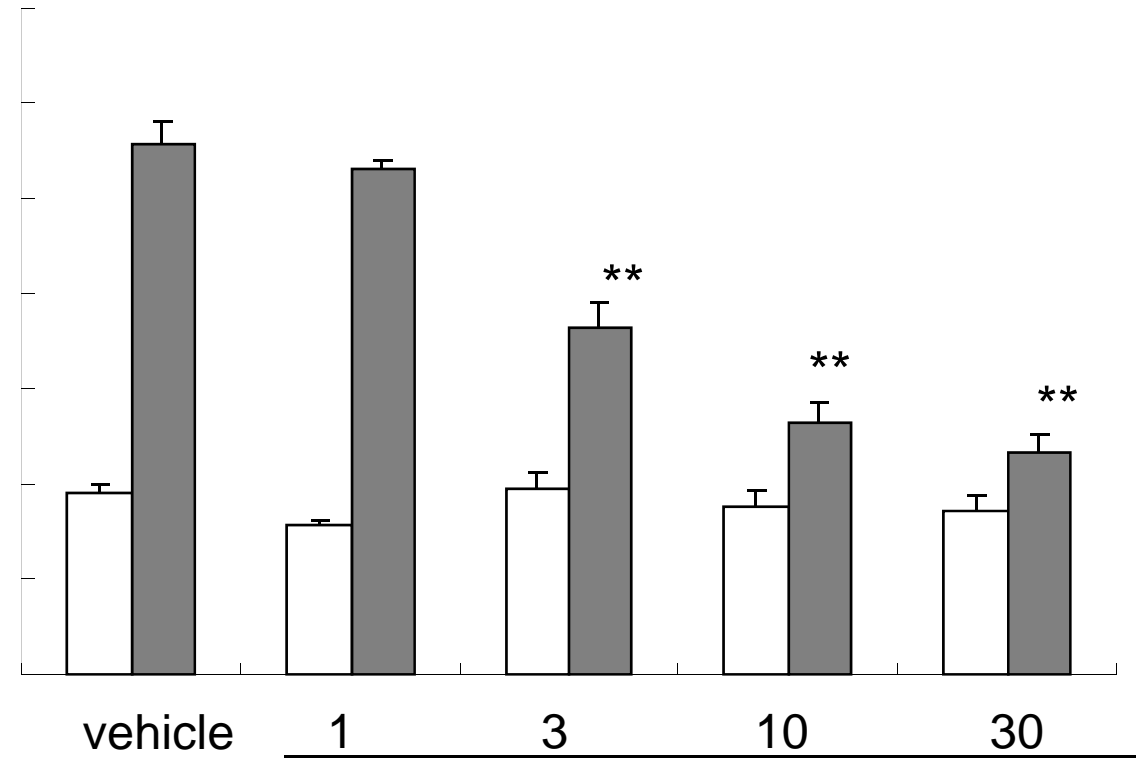


Fig.3.

A<smiles>CN1C(C(=O)Nc2ccccn2)=C(O)c2ccccc2S1(=O)=O</smiles><smiles>CCOCC(=O)CC(C)OC1=C(C(=O)Nc2ccccn2)N(C)S(=O)(=O)c2ccccc21</smiles><smiles>COC(=O)C1=C(O)c2ccccc2S(=O)(=O)N1</smiles><smiles>COC(=O)C1=C(O)c2ccccc2S(=O)(=O)N1C</smiles>

B
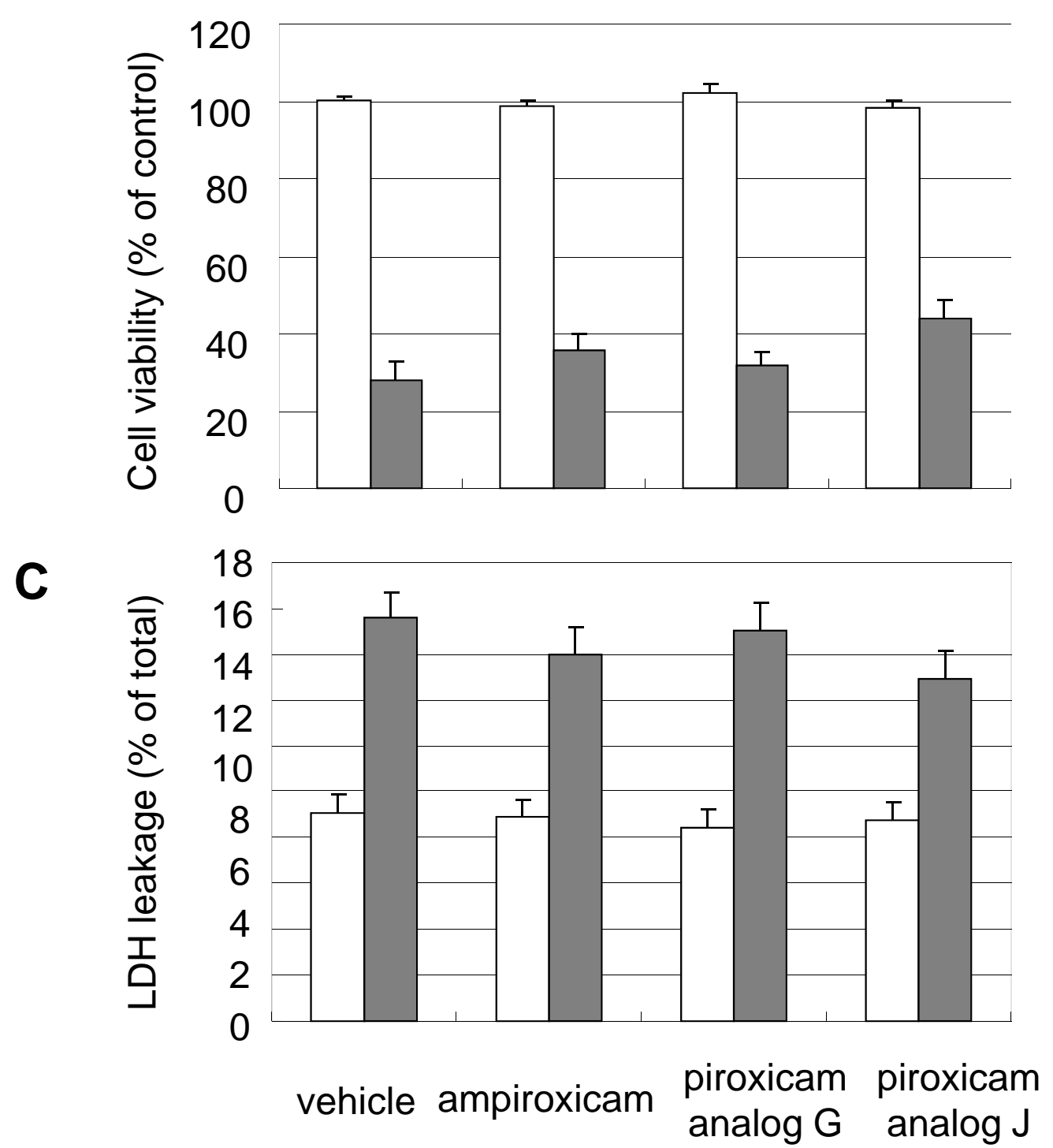
Fig.4.

A

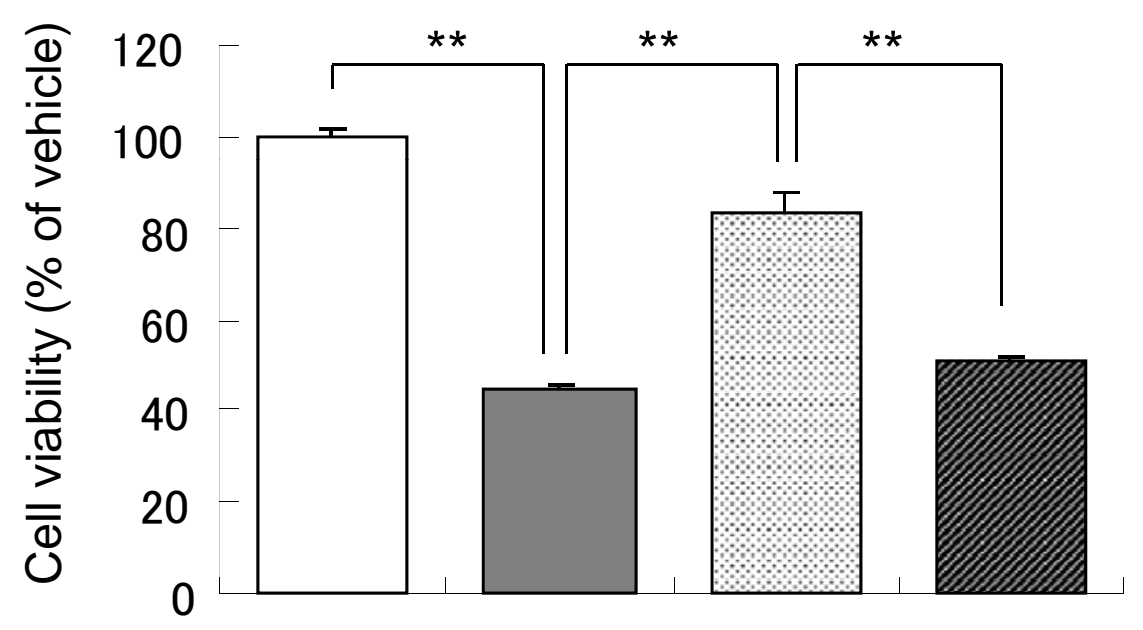

C

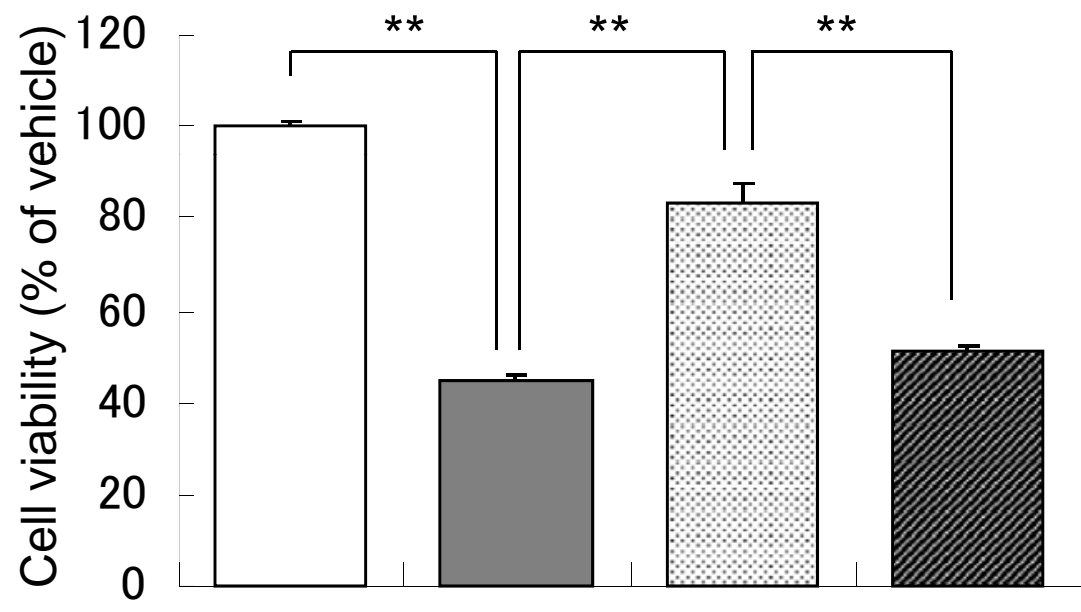

B

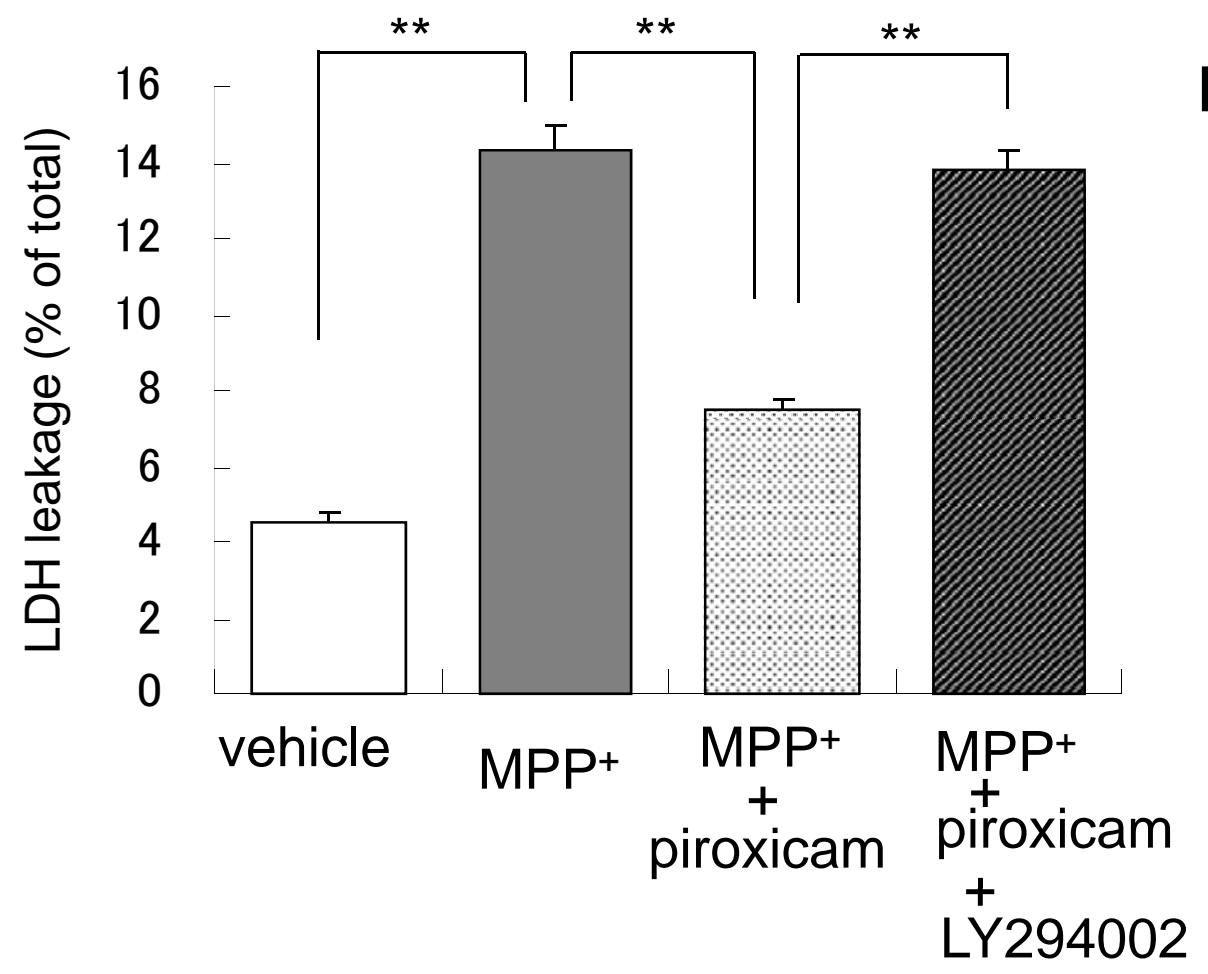

D

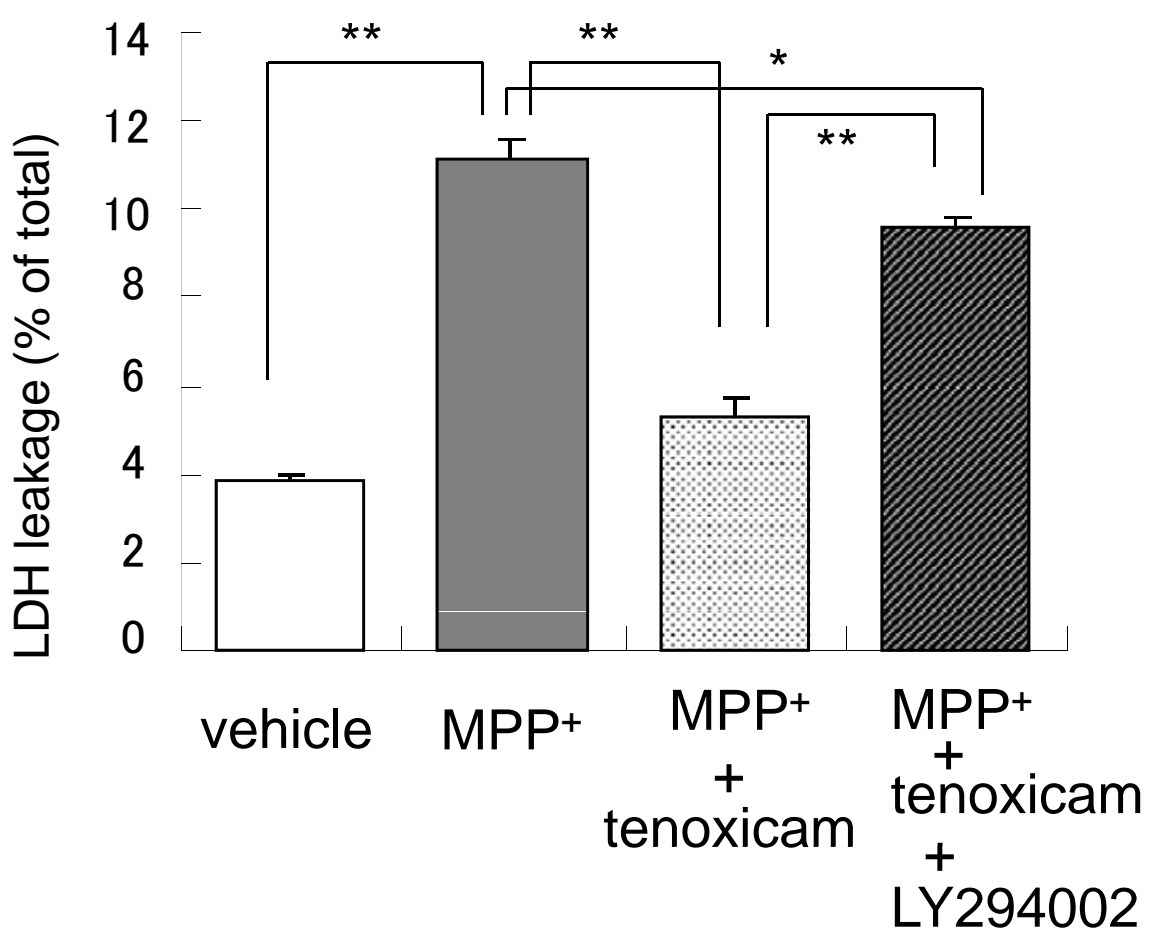


Fig.5.

A pAkt

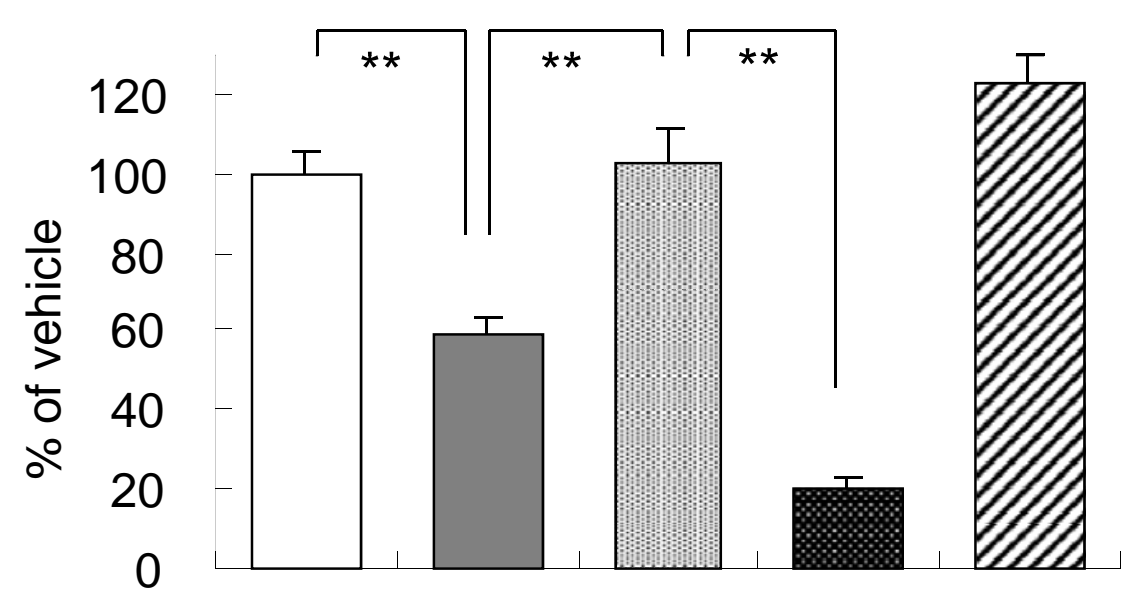

B Akt

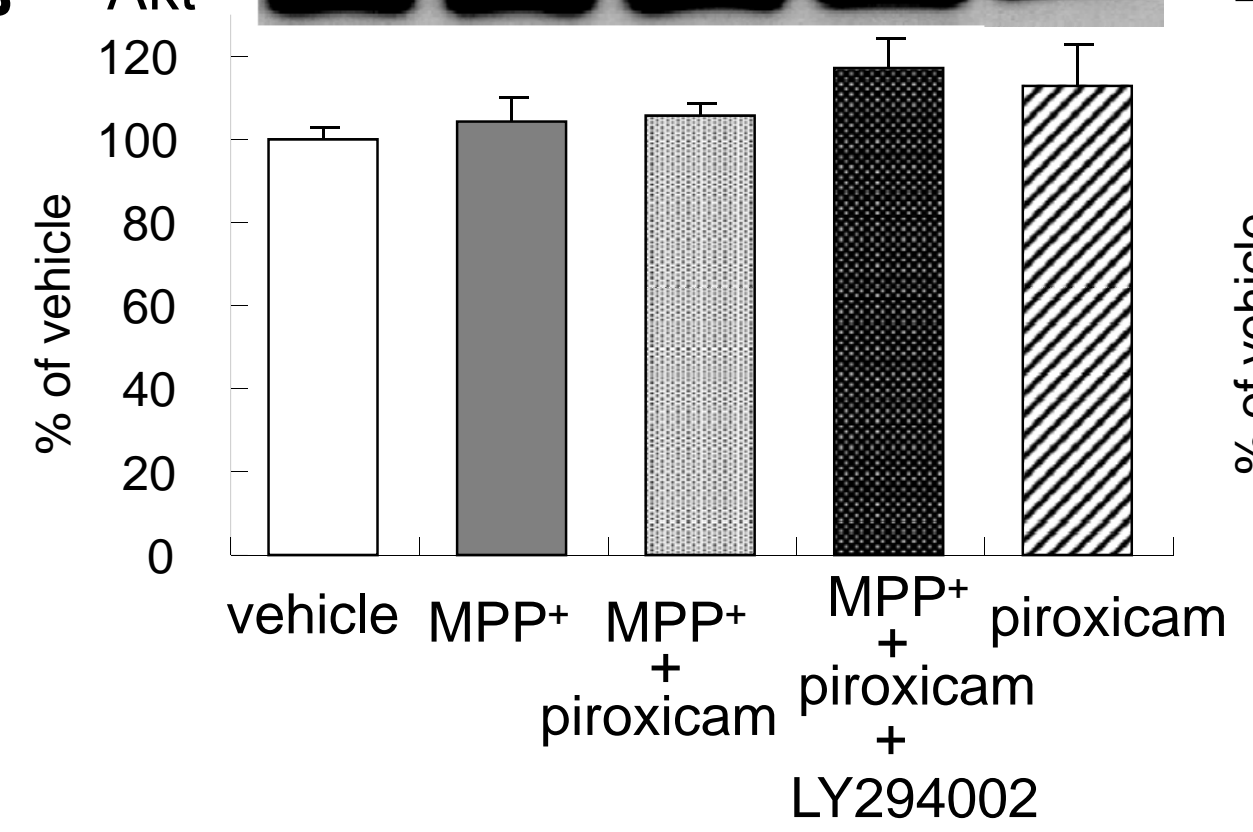

C pAkt

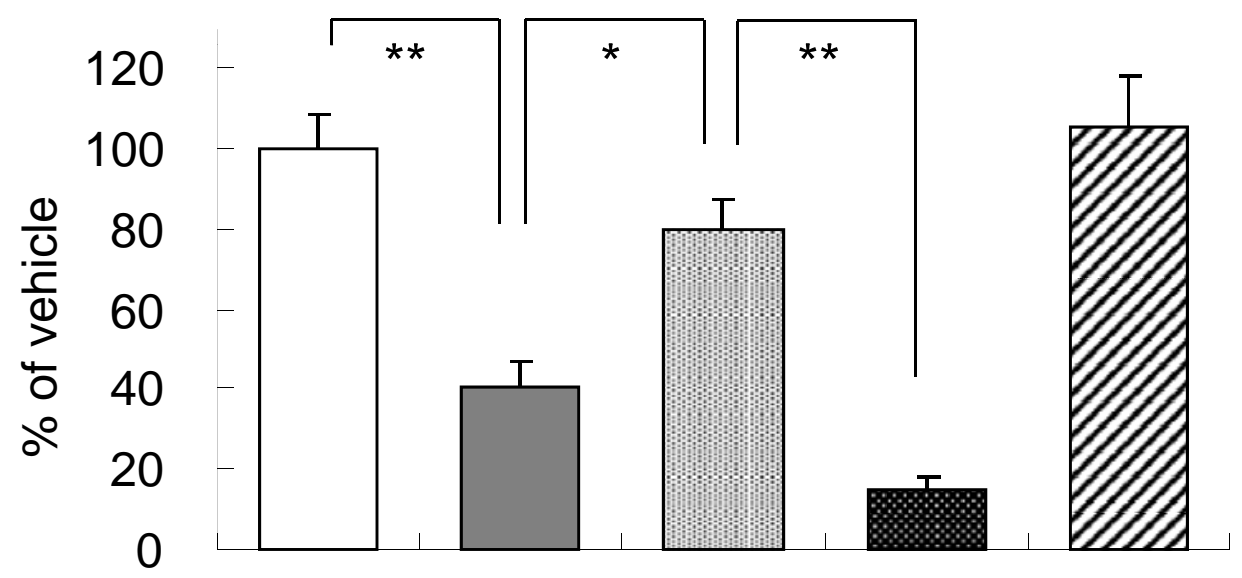

D Akt

120

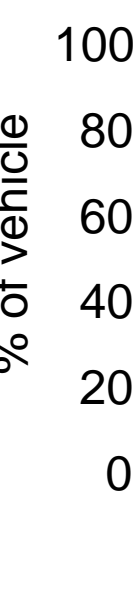

$\beta$-actin

$\beta$-actin 
Fig.6

A pAkt

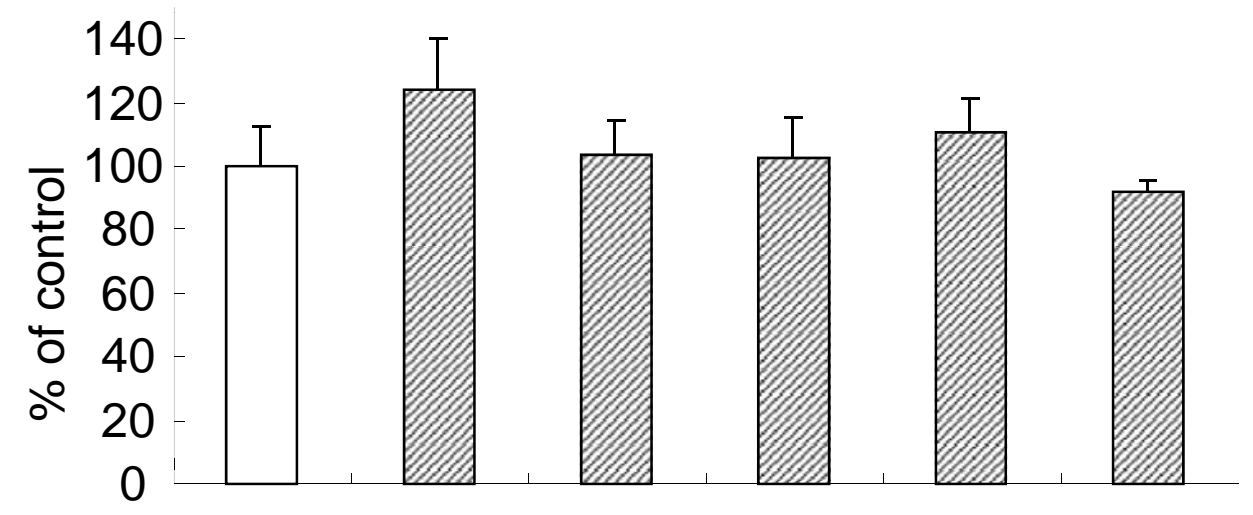

B Akt $\square \square$

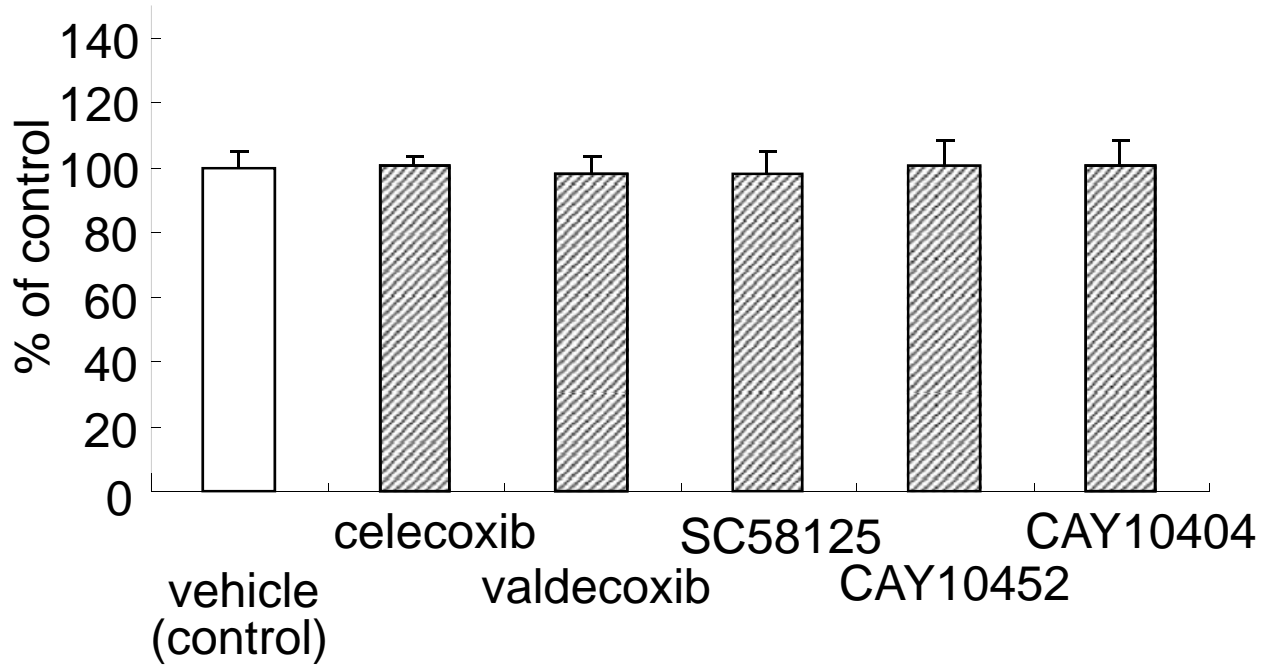

C pAkt

$$
140 \text { ᄂ }
$$

120

- 100

일 80

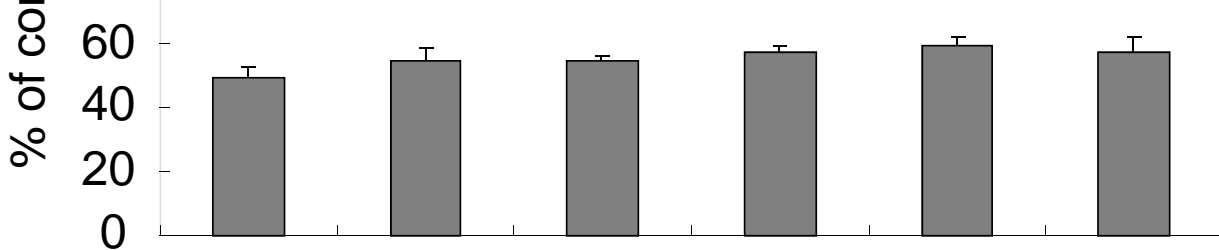

D Akt

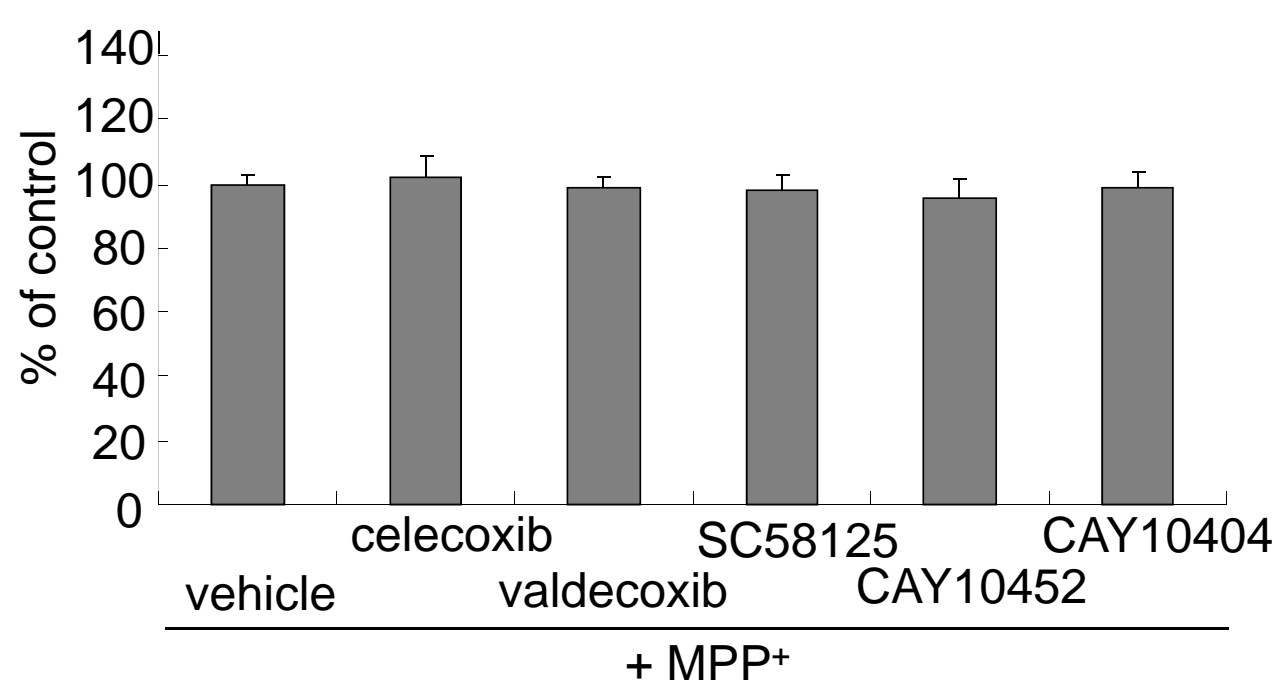


Fig.7
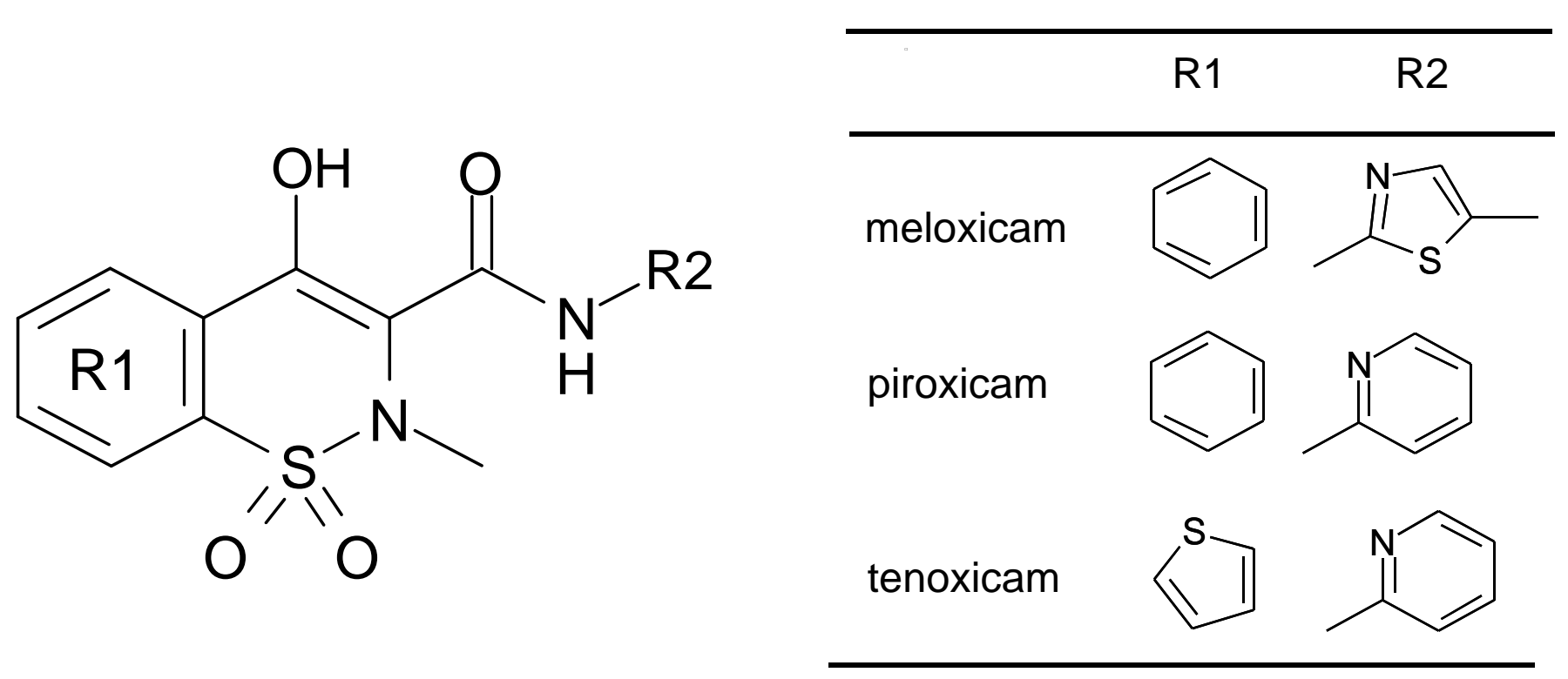


\section{Supp Fig.1}

A

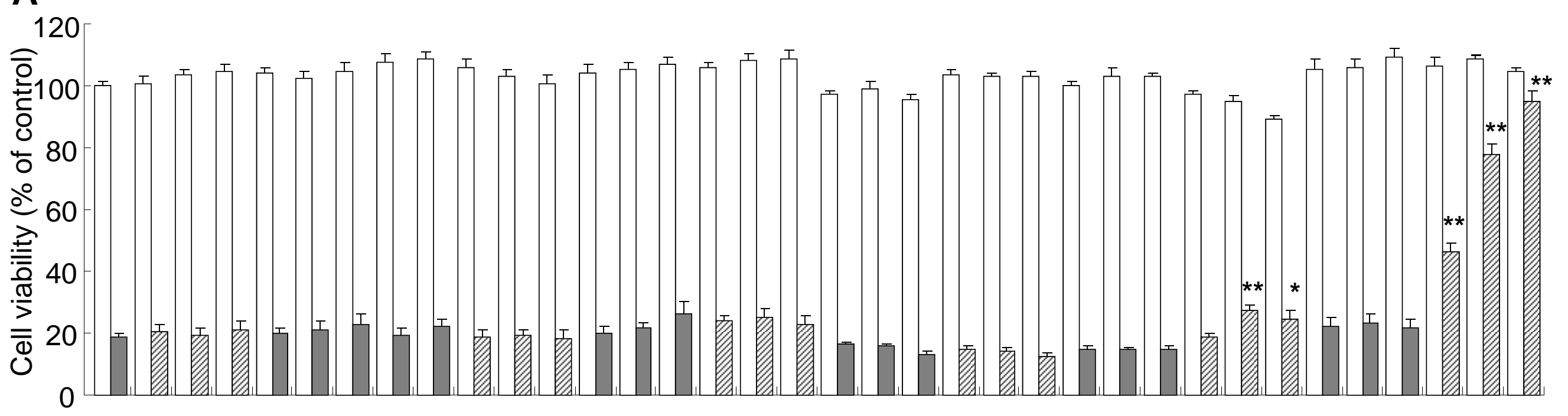

B

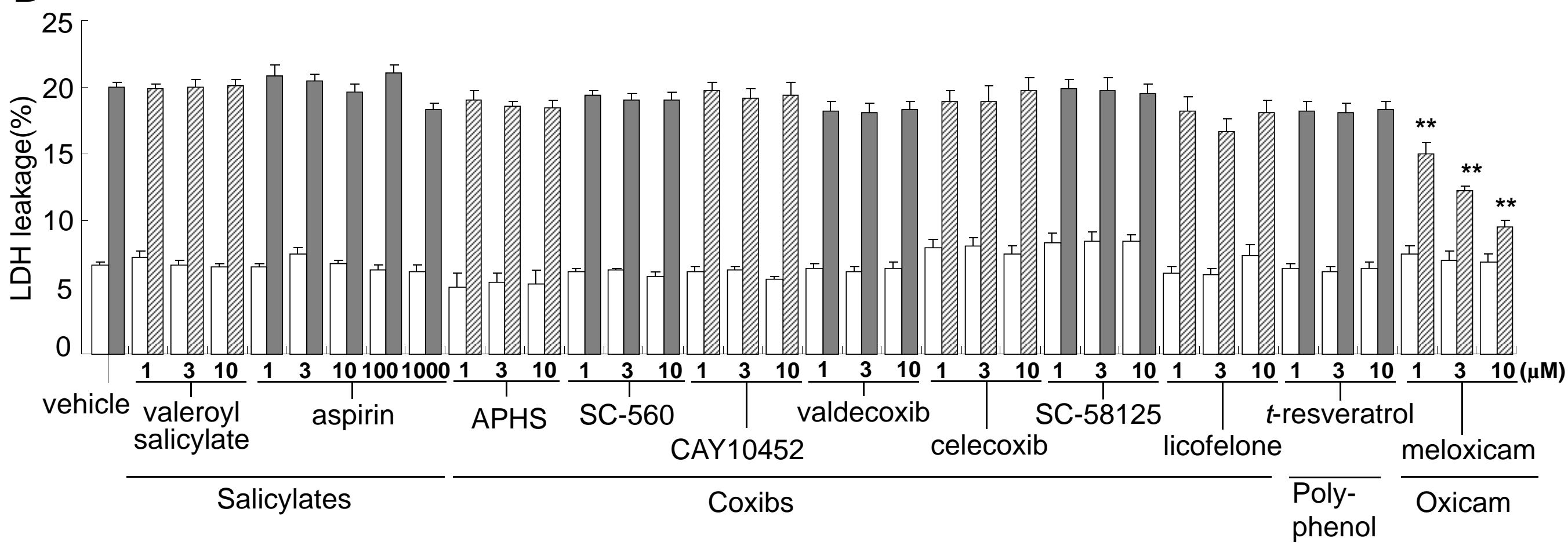

